\title{
Formation of Neutrophil Extracellular Traps under Low Oxygen Level
}

\begin{abstract}
Katja Branitzki-Heinemann ${ }^{1 \dagger}$, Helene Möllerherm ${ }^{1 \dagger}$, Lena Völlger ${ }^{1 \dagger}$, Diab M. Husein', Nicole de Buhr ${ }^{1,2}$, Stefanie Blodkamp ${ }^{1}$, Friederike Reuner', Graham Brogden', Hassan Y. Naim ${ }^{1}$ and Maren von Köckritz-Blickwede ${ }^{1,2 *}$
\end{abstract}

\begin{abstract}
${ }^{1}$ Department of Physiological Chemistry, University for Veterinary Medicine Hannover, Hanover, Germany, ${ }^{2}$ Research Center for Emerging Infections and Zoonoses (RIZ), University for Veterinary Medicine Hannover, Hanover, Germany
\end{abstract}

Since their discovery, neutrophil extracellular traps (NETs) have been characterized as a fundamental host innate immune defense mechanism. Conversely, excessive NETrelease may have a variety of detrimental consequences for the host. A fine balance between NET formation and elimination is necessary to sustain a protective effect during an infectious challenge. Our own recently published data revealed that stabilization of hypoxia-inducible factor $1 \alpha(\mathrm{HIF}-1 \alpha)$ by the iron chelating HIF- $1 \alpha$-agonist desferoxamine or AKB-4924 enhanced the release of phagocyte extracellular traps. Since HIF-1 $\alpha$ is a global regulator of the cellular response to low oxygen, we hypothesized that NET formation may be similarly increased under low oxygen conditions. Hypoxia occurs in tissues during infection or inflammation, mostly due to overconsumption of oxygen by pathogens and recruited immune cells. Therefore, experiments were performed to characterize the formation of NETs under hypoxic oxygen conditions compared to normoxia. Human blood-derived neutrophils were isolated and incubated under normoxic (21\%) oxygen level and compared to hypoxic (1\%) conditions. Dissolved oxygen levels were monitored in the primary cell culture using a Fibox4-PSt3 measurement system. The formation of NETs was quantified by fluorescence microscopy in response to the known NET-inducer phorbol 12-myristate 13-acetate (PMA) or Staphylococcus (S.) aureus wild-type and a nuclease-deficient mutant. In contrast to our hypothesis, spontaneous NET formation of neutrophils incubated under hypoxia was distinctly reduced compared to control neutrophils incubated under normoxia. Furthermore, neutrophils incubated under hypoxia showed significantly reduced formation of NETs in response to PMA. Gene expression analysis revealed that mRNA level of hif- $1 \alpha$ as well as hif- $1 \alpha$ target genes was not altered. However, in good correlation to the decreased NET formation under hypoxia, the cholesterol content of the neutrophils was significantly increased under hypoxia. Interestingly, NET formation in response to viable $S$. aureus wild-type or nuclease-deficient strain was retained under hypoxia. Our results lead to the conclusion that hypoxia is not the ideal tool to analyze HIF-1 $\alpha$ in neutrophils. However, the data clearly suggest that neutrophils react differently under hypoxia compared to normoxia and thereby highlight the importance of the usage of physiological relevant oxygen level when studying neutrophil functions.

Keywords: neutrophils, innate immunity, neutrophil extracellular traps, hypoxia, HIF-1 $\alpha$, cholesterol 


\section{INTRODUCTION}

Neutrophils belong to the first line of defense of the innate immune system against various pathogens including bacteria, fungi, and protozoa. Besides degranulation and the intracellular killing of pathogens, neutrophils are able to entrap and kill pathogens by the release of extracellular structures, so-called neutrophil extracellular traps (NETs) (1). NETs are formed upon activation in response to a wide range of stimuli, like interferon- $\alpha$, interleukin-8 (IL-8), the pharmacological agent phorbol 12-myristate 13-acetate (PMA), as well as numerous microbes and their products [reviewed by von Köckritz-Blickwede and Nizet (2)]. The formation of NETs is characterized by the disruption of the nuclear membrane, chromatin decondensation, and the mixing of nuclear contents with cytoplasmic and granular proteins. As a final step, the nuclear and granular components are released into the extracellular space (3). The fibrous DNA functions as a backbone in which histones, proteases [e.g., myeloperoxidase (MPO) and elastase], and antimicrobial peptides (AMPs) (e.g., cathelicidins) reside mediating their antimicrobial activity (4). The transcriptional regulation and intracellular signaling pathways of NET generation has not yet been fully investigated.

Generation of reactive oxygen species (ROS) is a key event for NET formation, and NET-based antimicrobial activity crucially depends on the formation of ROS through the membrane-bound NADPH oxidase enzyme complex as well as MPO $(3,5-9)$. Consequently, the most frequently used pathway to induce NETs is triggered by PMA, a protein kinase C (PKC) activator (1, $10,11)$. That, in turn, activates the NADPH oxidase complexsubunit $47^{\text {Phox }}(12)$ and thus strongly supports its activation. The produced superoxide anions serve as a starting product for additional ROS (13). Blocking the NADPH oxidase inhibits ROS generation and NET-release, respectively (14).

The downstream effects of ROS are extremely broad and range from the induction of NF- $\mathrm{KB}$ signaling (15), to peroxidation of phospholipids (16), or activation of the cell death receptor (17). Another interesting target of ROS is the hypoxia-inducible factor $1 \alpha(\mathrm{HIF}-1 \alpha)(18)$.

HIF-1 $\alpha$ was initially known to act as a transcriptional activator functioning as a master regulator of cellular and systemic oxygen homeostasis. Nowadays, HIF-1 $\alpha$ was additionally shown to play a role in the production of defense factors and to improve the bactericidal activity of myeloid cells $(19,20)$. Peyssonnaux and colleagues demonstrated in 2005 for the first time that HIF- $1 \alpha$ expression regulates the antibacterial capacity of phagocytes focusing on neutrophils and macrophages. HIF-1 $\alpha$ was induced by different bacterial pathogens including Staphylococcus (S.) aureus and Streptococcus pyogenes, even under normal oxygen levels (normoxia), and regulated the production of key immune effector molecules. Although the full spectrum of HIF- $1 \alpha$ downstream targets remains to be determined, the expression of a number of molecular effectors of host defense, including AMPs, TNF- $\alpha$, and the granule proteases cathepsin $\mathrm{G}$ and elastase, significantly correlated with HIF- $1 \alpha$ levels (19). Mice lacking HIF- $1 \alpha$ in their myeloid cell lineage showed decreased bactericidal activity and were not able to restrict a systemic spread of an infection from its initial tissue (19).
It was already shown that HIF- $1 \alpha$ is crucial in the formation of extracellular traps in mast cells [mast cell extracellular traps (MCETs)]. Augmentation of HIF-1 $\alpha$-activity resulted in a boosting of the antimicrobial activity of human and murine mast cells by inducing extracellular trap formation (21). At the same time, HIF- $1 \alpha$-deficient mast cells exhibited reduced antimicrobial activity and ability to form extracellular traps. Recently, it was reported that the mammalian target of rapamycin (mTOR), a highly conserved PI3K-like serine/threonine kinase and a posttranscriptional regulator of HIF- $1 \alpha$ protein expression, regulates the formation of NETs (22). As mTOR kinase is known as a key regulator of autophagy in many mammalian cells including neutrophils, it is hypothesized that mTOR plays a regulatory role in NET-release by regulating autophagic activity (23). Interestingly, McInturff et al. (22) also demonstrated that the iron chelating HIF-1 $\alpha$ agonist cobalt chloride $\left(\mathrm{CoCl}_{2}\right)$ triggered NET formation (22). Several authors discussed that the regulation of ROS generation could be a key factor in these HIF- $1 \alpha$ - and mTOR-mediated processes (22-24). Our own data confirm the hypothesis that HIF-1 $\alpha$ might be involved in the formation of NETs: the HIF- $1 \alpha$-agonist desferoxamine enhanced the release of extracellular traps in human and bovine neutrophils in a ROS-dependent manner (25).

Although the importance of HIF- $1 \alpha$ in the formation of NETs has already been stated, the impact of hypoxia on NET generation still needs to be clarified. Hypoxia was found to be able to enhance bactericidal activities of human neutrophils, increase their chemotactic, phagocytic, and respiratory burst capacities, and protect them from apoptosis $(19,26-29)$. Based on the described literature it may be hypothesized that NET formation increases under low oxygen conditions similarly to that shown by HIF- $1 \alpha$ stabilizing agents.

\section{MATERIALS AND METHODS}

\section{Bacterial Strains}

Staphylococcus aureus strain USA 300 wildtype (wt) (LAC AH 1263 ) and its nuclease mutant ( $\Delta$ nuc) (LAC AH 1680) (30) were used in this study. $S$. aureus was grown in brain heart infusion (BHI) medium at $37^{\circ} \mathrm{C}$ with shaking. Fresh overnight cultures were diluted 1:100 in $\mathrm{BHI}$ and then grown to mid-exponential growth phase $\left(\mathrm{OD}_{600}=0.7\right)$ until usage. Heat inactivation was performed for $30 \mathrm{~min}$ in $95^{\circ} \mathrm{C}$ hot water.

\section{Neutrophil Isolation}

Human blood-derived neutrophils were isolated from healthy donors in agreement with the local ethical board by density gradient centrifugation at $500 \times g$ using PolymorphPrep (Axis-Shield, Oslo, Norway) as previously described (31). Then, neutrophils were resuspended in RPMI 1640 (PAA, Freiburg, Germany) and plated on poly-L-lysine (\# P4707, Sigma-Aldrich) coated coverslips at a concentration of $2 \times 10^{5}$ cells/well in 48 -well plates or $5 \times 10^{5}$ cells/well in 24-well plates (Nunc, Germany).

\section{Oxygen Measurements}

Oxygen measurements were performed as previously described (32) using a Fibox4-PSt3 measurement system in 24-well plates 
(Nunc, Germany). Importantly, oxygen was measured non-invasively and was not consumed during the process of measurement. Freshly isolated neutrophils from human blood were adapted to hypoxia. Using optical sensors (placed on the bottom of the wells in the medium), the dissolved oxygen level in the cell culture media was measured based on the oxygen-dependent quenching of phosphorescent probes (32-34). Oxygen measurements were performed over a time period of $5 \mathrm{~h}$ while the cells were incubated under hypoxic $\left(7 \mathrm{mmHg}, 1 \% \mathrm{O}_{2}\right.$ ) or normoxic (159 $\mathrm{mmHg}, 21 \%$ $\mathrm{O}_{2}$ ) conditions, respectively.

\section{NET Induction and Visualization}

Neutrophils were preincubated under normoxic or hypoxic conditions for $2 \mathrm{~h}$ before they were subsequently infected with living or heat-inactivated bacteria (MOI 2) and incubated at $37^{\circ} \mathrm{C}$ and $5 \% \mathrm{CO}_{2}$ for $3 \mathrm{~h}$ under the respective oxygen condition. As a positive control to stimulate NET formation, $25 \mathrm{nM}$ PMA (Sigma, Hamburg, Germany) was used, while untreated neutrophils served as a negative control. Neutrophils were treated with $10 \mu \mathrm{g} / \mathrm{ml}$ diphenyleneiodonium (DPI) to block NADPH oxidase activity. Finally, cells were fixed with $4 \%$ paraformaldehyde (PFA; Roth, Germany).

Neutrophil extracellular traps were stained with an antibody against the histone-DNA complex (Millipore, mouse monoclonal anti DNA/Histone1 MAB 3864). Briefly, after blocking and permeabilization [ $2 \%$ BSA PBS $+0.2 \%$ Triton X-100 for 45 min at room temperature (RT)], samples were incubated for $1 \mathrm{~h}$ at RT with the primary antibody $(2.2 \mathrm{mg} / \mathrm{ml}$, diluted $1: 5000$ in PBS containing 2\% BSA, $0.2 \%$ Triton X-100). An Alexa Fluor 488-conjugated goat anti-mouse antibody (Thermo Scientific; diluted 1:1000 in PBS containing 2\% BSA, 0.2\% Triton X-100) was used as a secondary antibody. Slides were embedded in ProlongGold $^{\circledR}$ antifade with DAPI (P36931, Molecular Probes) and analyzed by confocal fluorescence microscopy using a Leica TCS SP 5 confocal microscope with a HCX PL APO 40× 0.75-1.25 oil immersion objective. Settings were adjusted in accordance to control preparations using the respective isotype control antibody. The total number of neutrophils and the number of neutrophils releasing NETs per field of view were counted in six representative images per sample.

\section{Lipid Isolation and Analysis}

A total of $5 \times 10^{6}$ neutrophils were incubated in a $1.5 \mathrm{ml}$ reaction tube for $3 \mathrm{~h}$ at either 1 or $21 \%$ oxygen. Samples were washed twice with PBS, resuspended in chloroform-methanol (1:1), and lysed by passing cells through a $45 \mathrm{~mm}$ cannula syringe 15 times. Subsequent lipid isolation was performed as previously described (35).
Cholesterol content was analyzed with a Hitachi Chromaster HPLC using a Chromolith ${ }^{\circledR}$ HighResolution RP-18 endcapped $100-4.6 \mathrm{~mm}$ column coupled to a $5-4.6 \mathrm{~mm}$ guard cartridge and heated to $32^{\circ} \mathrm{C}$. Methanol was used as the mobile phase at a flow rate of $1 \mathrm{ml} / \mathrm{min}$ at $22 \mathrm{bar}$, and a UV detector measuring at $202 \mathrm{~nm}$ to determine the amount of cholesterol in each sample. The results were quantified against an external standard ranging from 0.05 to $2 \mathrm{mg} / \mathrm{ml}$ cholesterol and expressed as nanogram cholesterol per $1 \times 10^{6}$ neutrophils.

Triglycerides, free fatty acids, monoacylglycerols, and phospholipids were analyzed by thin layer chromatography (TLC) based on a method described previously (35). Briefly, isolated lipid samples were loaded on silica gel plates (Merck, Germany) and separated based on polarity. Lipids were visualized by copper sulfate solution and the band intensities subsequently analyzed by CP Atlas (Lazer Software). Lipids were identified against a known standard. Each sample was analyzed in repetition.

\section{RNA Expression Analysis}

RNA was extracted from $5 \times 10^{5}$ neutrophils after incubation under normoxia or hypoxia for 2 or $3 \mathrm{~h}$, with the RNeasy Micro Kit (Qiagen) as described in the user's manual. RNA quality was tested with a bioanalyzer (RNA 6000 Pico Kit, Agilent) following the manufacturer's instructions. Real-time PCR of reverse transcribed RNA (RT-qPCR) was designed to analyze expression of genes of interest and the housekeeping gene rps9. The respective primers are given in Table 1. The RT-qPCR was conducted as previously described (36) with the following modified program: initial denaturation at $95^{\circ} \mathrm{C}$ for $20 \mathrm{~min}$ and 40 cycles of denaturation at $95^{\circ} \mathrm{C}$ for $25 \mathrm{~s}$, annealing at $58^{\circ} \mathrm{C}$ for $30 \mathrm{~s}$, and amplification at $72^{\circ} \mathrm{C}$ for $20 \mathrm{~s}$ using an AriaMX Real-Time PCR system. Products were verified by melting curve analysis and $1.5 \%$ agarose gel electrophoresis. Data were normalized to a non-regulated housekeeping gene (rps9). The relative $\Delta \mathrm{CT}$ values were determined for expression of the genes hif-1 $\alpha, l l-37$, and vegf. CT is the cycle number at the chosen amplification threshold, $\Delta \mathrm{CT}=\mathrm{CT}$ gene (11-37) $-\mathrm{CT}$ reference (rsp9) and $\Delta \Delta \mathrm{CT}=\Delta \mathrm{CT}$ sample $-\Delta \mathrm{CT}$ calibrator. The fold change in expression $\left(2^{-\Delta \Delta C T}\right)$ was calculated as the read-out parameter. The calibrator was neutrophils under normoxia.

\section{Statistical Analysis}

All experiments were performed at least three independent times unless indicated otherwise. Data were analyzed using Excel 2010 (Microsoft) and GraphPad Prism 6.0 (GraphPad Software). Differences between two or more groups were analyzed by using a two-way ANOVA with Sidak's multiple comparisons test if not otherwise stated. The significance is indicated as follows: n.s., not significant, ${ }^{*} p \leq 0.05,{ }^{* *} p \leq 0.01,{ }^{* *} p \leq 0.001$, and ${ }^{* * * *} p<0.0001$.

TABLE 1 | Oligonucleotide primers used in RT-qPCR.

\begin{tabular}{|c|c|c|c|}
\hline Gene & Primer sequence $\left(5^{\prime}-3^{\prime}\right)$ forward & Primer sequence $\left(5^{\prime}-3^{\prime}\right)$ reverse & Amplicon length (bp) \\
\hline hif- $1 \alpha$ & GATGGAAGCACTAGACAAAGTTCA & ATCAGTGGTGGCAGTGGTAGTG & 360 \\
\hline vegf & ATGAACTTTCTGCTGTCTTGGGT & TGGCCTTGGTGAGGTTGATCC & 344 \\
\hline
\end{tabular}




\section{RESULTS AND DISCUSSION}

\section{Low Oxygen Levels in In Vitro Neutrophil Suspension Culture}

At sites of infection and inflammation, the environmental oxygen concentration decreases and can drop to $1 \%$ due to invading pathogens and translocating immune cells, including neutrophils, with consequences for cellular functions $(34,37-39)$. To study the effect of hypoxia, freshly isolated human neutrophils were seeded and incubated under normoxic compared to $1 \%$ hypoxic conditions, and the oxygen level in the wells was measured over a time period of $5 \mathrm{~h}$ as described above. When cultured under normoxia, the neutrophil cultures maintained a constant oxygen level that reflected the atmospheric condition at around $165 \mathrm{mmHg}\left(22.3 \pm 0.46 \% \mathrm{O}_{2}\right)$. In contrast, hypoxic incubation decreased the dissolved oxygen level in the culture to less than $37 \mathrm{mmHg}\left(4.9 \pm 0.2 \% \mathrm{O}_{2}\right)$ within $45 \mathrm{~min}$ and resulted in an equilibration lower than $13.3 \mathrm{mmHg}\left(1.79 \pm 0.03 \% \mathrm{O}_{2}\right)$ within $5 \mathrm{~h}$ (Figure 1). Our results indicate that the applied experimental settings by incubating neutrophils under hypoxia decrease the oxygen level and reflect physiological oxygen conditions that may occur in infected tissue.

\section{Spontaneous and PMA-Induced Net Formation under Hypoxia Compared to Normoxia}

To study the effect of hypoxia on the spontaneous and PMAinduced NET formation, neutrophils were preincubated for $2 \mathrm{~h}$ at the defined oxygen concentration (normoxia and hypoxia, as shown in Figure 1). After an additional $3 \mathrm{~h}$ of incubation in the

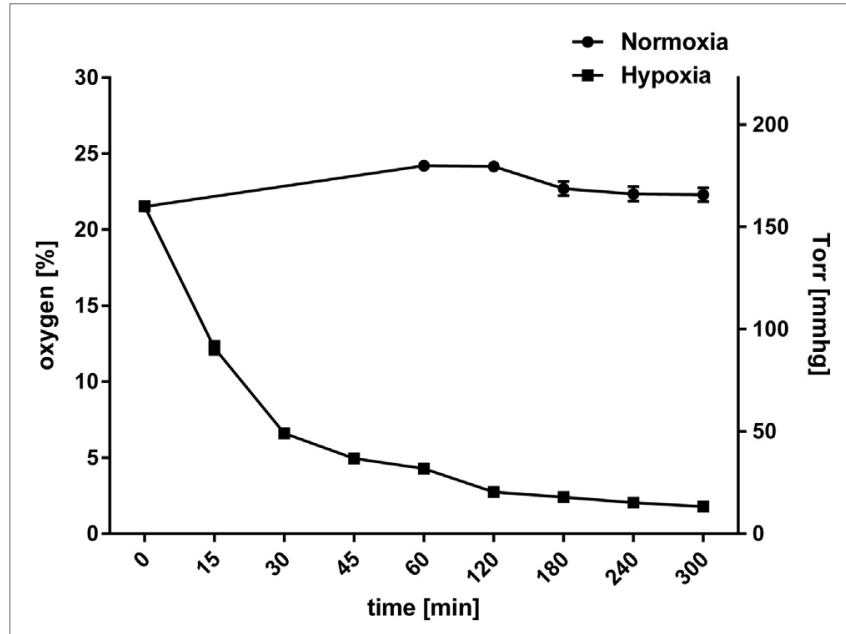

FIGURE 1 | Oxygen levels in neutrophil suspension cultures Neutrophils were incubated under normoxia (21\%) or hypoxia (1\%). Dissolved oxygen levels in neutrophil suspension culture were monitored for $5 \mathrm{~h}$. Plotted values represent mean \pm SEM and are displayed as \% oxygen on the left $y$-axis and $\mathrm{mmHg}$ oxygen on the right $y$-axis. Starting at $21.5 \pm 0.14 \%$ (normoxia) and $21.5 \pm 0.21 \%$ (hypoxia) after $5 \mathrm{~h}$, the oxygen level dropped to $1.79 \pm 0.03 \%$ under hypoxia, while it stayed relatively constant around $22.3 \pm 0.46 \%$ under normoxia. presence or absence of PMA, the neutrophils were analyzed for their NET-releasing capability.

An amount of $11.6 \pm 1.0 \%$ of untreated neutrophils spontaneously formed NETs under normoxia (Figure 2). Interestingly, incubation under hypoxia distinctly reduced the number of spontaneously NET forming neutrophils to $7.1 \pm 0.7 \%$ (Figures 2A,B).

However, as previously published $(1,3)$ and confirmed here (Figure 2), approximately $90 \%$ of cells were found to release NETs after incubation at an atmospheric oxygen concentration in response to PMA. Importantly, hypoxic pretreatment of neutrophils completely abolished the PMA-induced NET formation seen at normoxic conditions (Figure 2). It is well known, that the PMA-dependent NET formation is based on the generation of ROS $(1,7)$. In good correlation to these findings, Kirchner et al. (40) recently confirmed that the formation of ROS is blocked at $2 \% \mathrm{O}_{2}$ and also leads to an abrogated NET-release. Furthermore, a broad spectrum of antioxidative substances such as flavonoids, vitamin $\mathrm{C}$, and aminosalicylic acid were also shown to inhibit NET formation through the reduction of ROS (41).

\section{Gene Expression of hif-1 $\alpha$ and Target Genes}

As already mentioned in the Section "Introduction," HIF- $1 \alpha$ is an essential regulator to modulate cellular stress responses to low oxygen conditions and also has been shown to modulate the formation of NETs $(22,25)$. Therefore, the mRNA expression of this transcription factor as well as two of its target genes (vegf and $l l-37)(42-44)$ were investigated in neutrophils incubated under normoxia versus $1 \%$ hypoxia with RT-qPCR.

As depicted in Figure 3, the expression level of hif- $1 \alpha$ or its target genes did not change neither after $2 \mathrm{~h}$ (Figure 3A) nor after $3 \mathrm{~h}$ (Figure 3B) incubation under hypoxia compared to normoxia. All $\Delta \Delta \mathrm{CT}$ values remained around 1 meaning that there were no differences in the gene expression levels of the neutrophils that were cultivated under normal oxygen level in comparison to those cultivated under low oxygen levels. Therefore, short-time treatment at $1 \%$ hypoxia for 2 or $3 \mathrm{~h}$ might not be the optimal model to study the HIF-1 $\alpha$-dependent response of neutrophils. Moreover, HIF- $1 \alpha$ might not be responsible for the altered NET-phenotype under hypoxia shown in Figures 2A,B. It seems that neutrophils need an additional trigger to induce the expression of $h i f-1 \alpha$ as hypoxia alone does not alter the expression level under the selected conditions (Figures 3A,B). In good correlation to our RT-qPCR results, Kirchner et al. (41, 40) also exhibited that hypoxia alone did not stabilize HIF- $1 \alpha$ protein level. Interestingly, those authors demonstrated that $\mathrm{HIF}-1 \alpha$ is stabilized under hypoxia as wells as under normoxia by stimulating neutrophils with PMA (41).

\section{Lipid Alterations}

Previous data revealed that lipid alterations modulate the formation of NETs (45): decreased level of cholesterol mediated by methyl- $\beta$-cyclodextrin in primary blood-derived neutrophils led to increased spontaneous NET formation. Furthermore, pharmacological treatment of neutrophils with statins that 

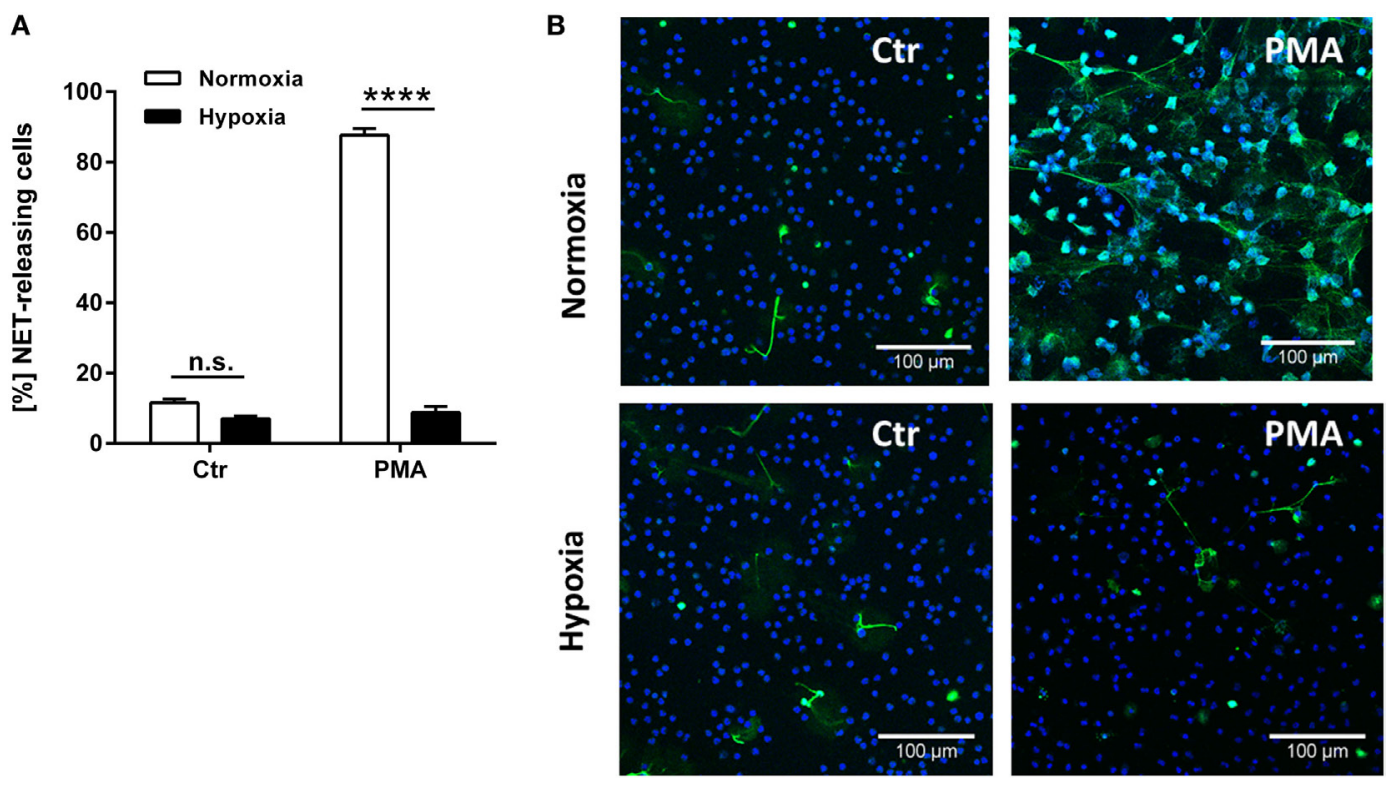

FIGURE 2 | Spontaneous and PMA-induced NET-release is decreased under hypoxia. Neutrophils were incubated for $2 \mathrm{~h}$ under normoxia or hypoxia before treatment with $25 \mathrm{nM}$ PMA for additional $3 \mathrm{~h}$. Formation of NETs was visualized using a monoclonal antibody against histone-DNA complexes (green) in combination with DAPI to stain the nuclei (blue). (A) Under normoxia NET-release was stimulated with PMA in $87.7 \pm 1.8 \%$ of the cells, while $11.6 \pm 1.0 \%$ of the neutrophils formed NETs spontaneously. Incubation under hypoxia decreased the spontaneous NET-release to $7.1 \pm 0.7 \%$ and abrogates the PMA-stimulatory effect to a rate of $8.8 \pm 1.7 \%$. (B) Representative fluorescence micrographs depicting NET-release of neutrophils. Statistical analysis of was performed with one-tailed paired Student's t-test.
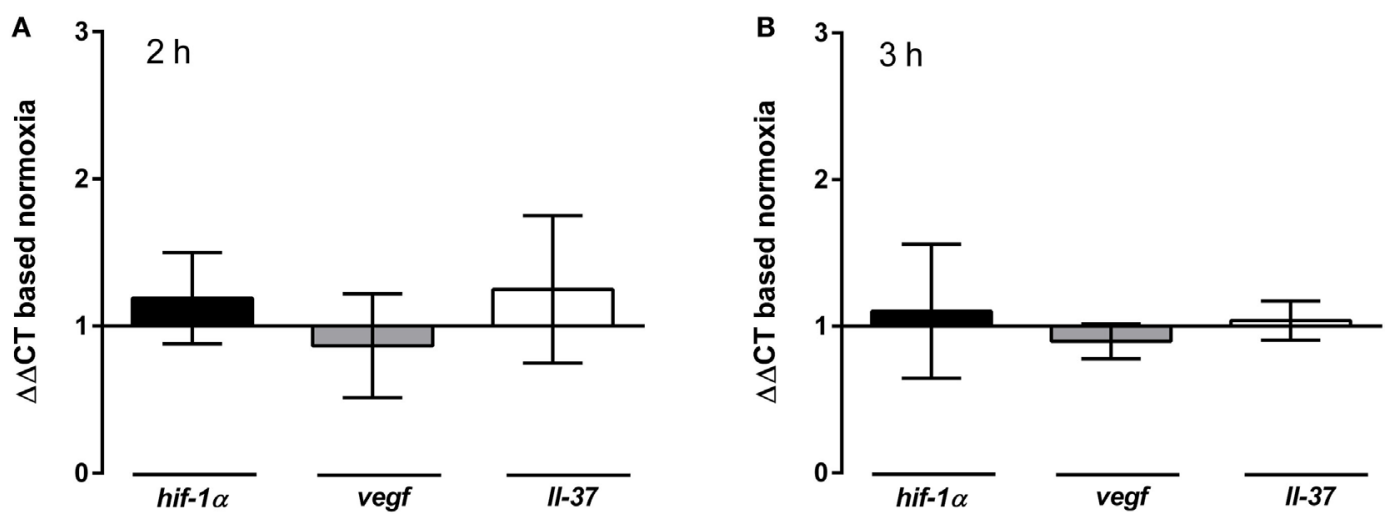

FIGURE 3 | Gene expression of hif-1 $\boldsymbol{\alpha}$ and target genes. Neutrophils were incubated under normoxia or hypoxia for $2 \mathrm{~h}$ (A) and $3 \mathrm{~h}$ (B) before RNA was isolated and gene expression of hif- $1 \alpha$ and its target genes vegf and II-37 was analyzed by RT-qPCR. Data were normalized to the non-regulated housekeeping gene rps9. The $x$-fold changes of the values from samples incubated under hypoxia were calculated against the normoxic samples. Independent of the time point, there was neither a regulation of hif- $1 \alpha$ nor of its target genes vegf and Il-37 detectable, as all $\Delta \Delta \mathrm{CTs}$ remain below 2 [hif- $1 \alpha: 1.19 \pm 0.3$ ( $2 \mathrm{~h})$ and $0.1 \pm 0.5$ ( $3 \mathrm{~h})$; vegf: $0.87 \pm 0.4(2 \mathrm{~h})$ and $0.9 \pm 0.1(3 \mathrm{~h}) ; 1 /-37: 1.25 \pm 0.5(2 \mathrm{~h})$ and $1.0 \pm 0.1(3 \mathrm{~h})]$

block cholesterol synthesis also induce formation of NETs (46). Therefore, we here compared the lipid composition of the neutrophils when incubated under normoxia versus hypoxia by TLC. The data shown in Figure 4A demonstrate substantial lipid alterations comparing hypoxic and normoxic conditions, e.g., cholesterol. To verify the results, HPLC was used to quantify the cholesterol level in the cells. In good correlation to these data, a significant higher cholesterol level was found in cells after incubation under hypoxia compared to normoxia (Figure 4B) at the same time when decreased spontaneous NET formation was detectable in control cells (Figures $\mathbf{2 A}, \mathbf{B}$ ). Thus, it may be speculated that hypoxia-mediated changes in lipid content, e.g., cholesterol accumulation in the cell may contribute to altered spontaneous NET formation under hypoxia.

\section{S. aureus-Induced NET Formation}

Even though the RT-qPCR results reveal no exclusive link of HIF$1 \alpha$ to hypoxia, our data are consistent: the absence of sufficient 

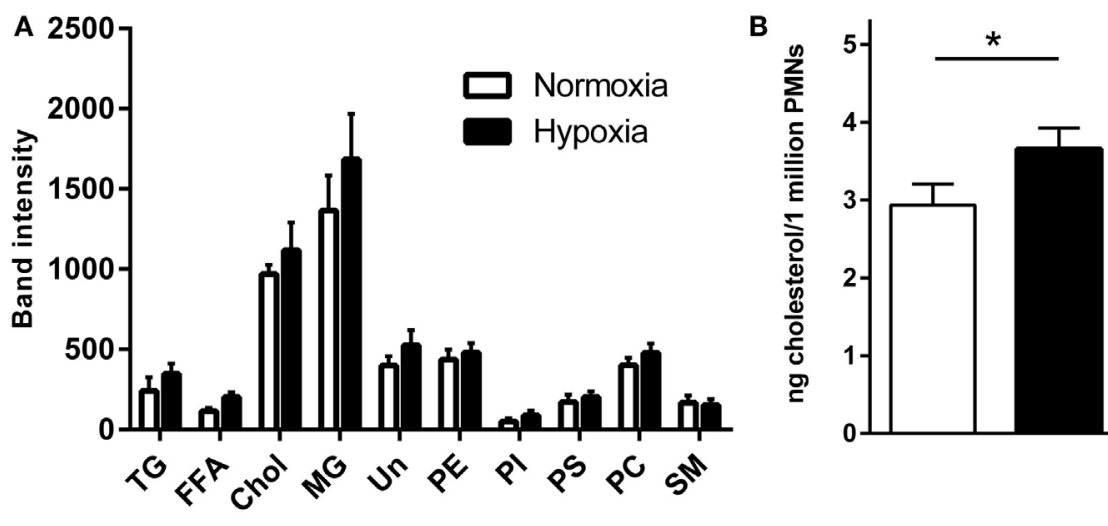

FIGURE 4 | The cellular cholesterol content increased under hypoxia. Neutrophils were incubated in either 1 or $21 \%$ oxygen, and their lipid composition was analyzed by TLC (A): triglycerides (TG), free fatty acids (FFA), cholesterol (chol), monoacylglycerols (MG), unknown (UN), phosphatidylethanolamine (PE), phosphatidylinositol (PI), phosphoserine (PS), phosphatidylcholine (PC), and sphingomyelin (SM). Furthermore, cholesterol content was analyzed via HPLC (B). Results are expressed as nanogram cholesterol per $1 \times 10^{6}$ neutrophils. A significant higher cellular cholesterol level was detectable after incubation under hypoxia compared to normoxia. Statistical analysis was performed with one-tailed paired Student's $t$-test.

oxygen combined with the lack of HIF-1 $\alpha$ signaling and increased cholesterol level hamper the formation of extracellular traps in neutrophils.

Nevertheless, we were interested if a bacterial stimulus could affect NET-release even under the above described condition. Therefore, it was of special interest to analyze the S. aureus-induced NET formation at low oxygen levels in more detail. The $S$. aureus wt strain and its nuclease-deficient $\Delta n u c$ mutant were used in parallel, since the $\Delta n u c$ mutant enables better visualization of full length NETs, which are not shortened by $S$. aureus nuclease. However, both strains are known to induce NET formation at similar level (30). Similar to the PMA-stimulated approach, neutrophils were incubated under hypoxia or normoxia for $2 \mathrm{~h}$ before bacteria were added, and the cells were further cocultivated with $S$. aureus for $3 \mathrm{~h}$ under consistent oxygen conditions.

Interestingly, the amount of NET-releasing cells was not abrogated in the absence of $\mathrm{O}_{2}$ : living bacteria induced comparable amounts of NET-releasing cells under normoxia as well as under hypoxia (Figure 5A: S. aureus wt: $33.9 \pm 10.8 \%$ normoxia compared to $36.6 \pm 8.0 \%$ hypoxia; Figure 5B: $S$. aureus $\Delta n u c$ : $43.6 \pm 4.96 \%$ normoxia compared to $43.6 \pm 12.3 \%$ hypoxia) These results confirm the existing literature and emphasize that living $S$. aureus have the capacity to stimulate NET formation independent of oxygen concentration $(47,48)$. In contrast to viable $S$. aureus, h.i. S. aureus was no longer able to induce NET formation under hypoxia with the same efficiency compared to normoxia, indicating a different oxygen-dependent mechanism triggered by dead S. aureus (Figure 5C: $31.8 \pm 4.3 \%$ normoxia compared to $20 \pm 2.8 \%$ hypoxia).

So far, different bacterial factors that are released by viable bacteria have been described to trigger the formation of NETs in response to $S$. aureus infections: the $\mathrm{N}$-terminal $\mathrm{ArgD}$ peptides (49), leukotoxin GH (47), and Panton-Valentin leukocidin (PVL) (48). Importantly, those exotoxins trigger formation of NETs by completely different mechanisms. The PVL-mediated NET formation is described as a vesicular release of nuclear DNA by a mechanism independent of NADPH oxidase. In contrast, the leukotoxin GH and ArgD peptides-mediated NET formation is associated with cytolysis (no vesicular release of nuclear DNA), which is in accordance with the initial data from Fuchs et al. (3), who described the NADPH-oxidase-dependent formation of NETs in response to $S$. aureus as a novel cell death later called "NETosis" (50).

To further characterize the role of NADPH oxidase-mediated production of ROS in the $S$. aureus-mediated NET formation under $1 \%$ oxygen, we treated neutrophils with DPI to block NADPH oxidase. As shown in Figure 5D, treatment of neutrophils with DPI significantly decreased the $S$. aureus $\Delta n u c$ mediated formation of NETs under hypoxia and normoxia as also previously shown by Fuchs et al. (3) under normoxia. These data indicate that under hypoxic as well as normoxic conditions, NADPH oxidase contribute to the formation of NETs in response to $S$. aureus. Since residual NET formation is still detectable in the presence of DPI (Figure 5D), additional pathways might also contribute to the phenotype as described by Pilsczek et al. (48). Under consideration of the lipid data shown in Figure 4, it might also be speculated that lipid alterations found under hypoxia lead to altered susceptibility of the neutrophil to bacterial exotoxins and/or oxidative stress as also shown by Chow et al. (46), and that these cellular changes modulate the neutrophil ability to release NETs. However, further studies are needed to prove this hypothesis.

Interestingly, our data obtained from the PMA- or S. aureusstimulated neutrophils revealed a highly specific response, namely a characteristic NET formation level, to a distinct stimulus under various oxygen conditions. Whereas the NET formation mediated by viable $S$. aureus remains preserved under hypoxia (Figures $\mathbf{5 A}, \mathbf{B}$ ), the NET formation in response to PMA (Figures 1 and 5D) or dead S. aureus (Figure 5C) is reduced under hypoxia. However, the data shown here highlight that neutrophils can react completely different to the same trigger under hypoxia compared to normoxia. Since neutrophils are prominent immune 

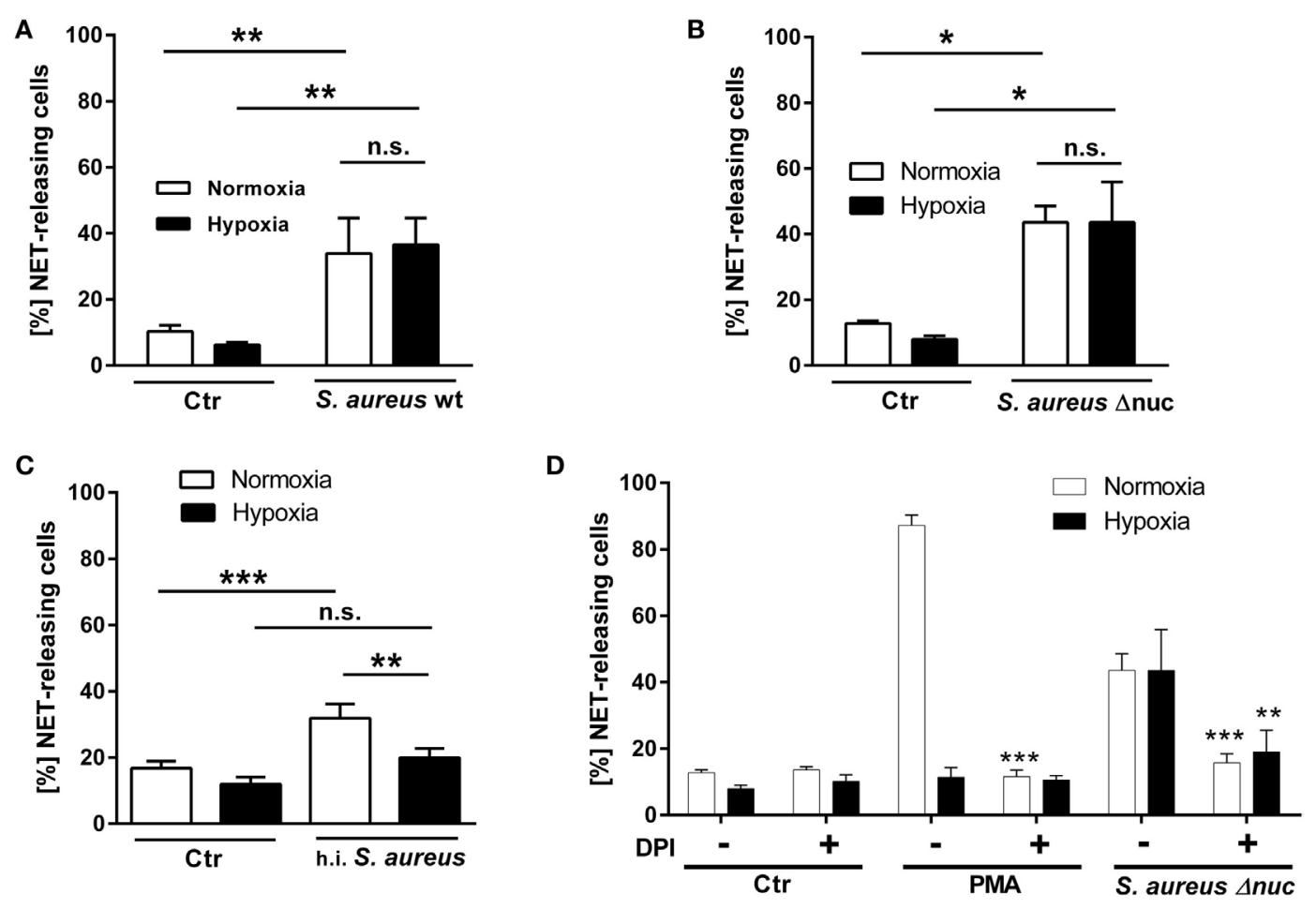

FIGURE 5 | S. aureus-induced NET formation. Neutrophils were preincubated under normoxic or hypoxic conditions for 2 h and further co-incubated for $3 \mathrm{~h}$ under the respective oxygen concentration with S. aureus wt (living and h.i.) and S. aureus $\Delta$ nuc. Formation of NETs was microscopically analyzed and calculated as (\%) NET-releasing cells. Neutrophils stimulated with S. aureus wt (A) and S. aureus $\Delta$ nuc (B) release significantly more NETs compared to the amount of spontaneous NET formation both under normoxia as well as under hypoxia (normoxia: $S$. aureus wt: $33.9 \pm 10.8 \%$ and ctr: $10.3 \pm 1.9 \% / S$. aureus $\Delta$ nuc: $43.6 \pm 5 \%$ and ctr: $12.8 \pm 0.9 \%$, hypoxia: S. aureus wt: $36.9 \pm 12.8 \%$ and ctr: $8 \pm 1.1 \% / S$. aureus $\Delta$ nuc: $43.6 \pm 12.3 \%$ and ctr: $8 \pm 1.1 \%$ ). (C) The h.i. S. aureus caused significantly higher numbers of NET-releasing cells compared to untreated control under normoxia, while this difference was highly decreased under hypoxic conditions (normoxia: h.i. S. aureus: $31.8 \pm 4.3 \%$ and ctr: $16.8 \pm 2.1 \%$, hypoxia: h.i. S. aureus: $20 \pm 2.8 \%$ and ctr: $12.3 \pm 2.1 \%$ ), $n=2$ independent experiments with each $n=6$ images (total $n=12$ ). (D) Neutrophils were treated with $10 \mu \mathrm{g} / \mathrm{ml}$ DPI to block NADPH oxidase activity. Formation of NETs was statistically analyzed compared to respective control in the absence of DPI by one-tailed unpaired Student's $t$-test.

cells found in inflamed tissue associated with low oxygen levels, hypoxia mimics the physiologic situation during an inflammation or infection much more accurately $(34,51)$. The described model should therefore be preferably used instead of the standard in vitro models, including the standardized NET induction assay, which are performed under normoxic conditions. Finally, in light of these results it should also be discussed if data obtained from studies performed under normoxia are really physiologically relevant. This is especially interesting since the formation of NETs was also implicated in the development of tumor-related diseases (52). Recently, Tohme et al. showed that NETs promote the development and progression of liver metastases after surgical stress. Importantly, in growing metastatic tumors, the authors found that intratumoral hypoxia accentuated NET formation (53). In line of this study, Alfaro et al. (54) demonstrated that tumor-produced IL-8 leads to extrusion of NETs in human myeloid-derived suppressor cells, which are considered an important T-cell immunosuppressive component in cancer-bearing hosts (54). Based on these data, it may be suggested that the elimination of NETs or pharmacological blocking of NET formation may reduce risks of tumor relapse. Thus, for a better understanding of the neutrophil biology as a target for new therapeutic interventions it is urgently needed to study its activity under specific physiological relevant oxygen conditions.

\section{ETHICS STATEMENT}

This study was carried out in accordance with the recommendations of the Medizinische Hochschule Hannover Ethics Committee (Ethics Statement No. 3295-2016).

\section{AUTHOR CONTRIBUTIONS}

MK-B, LV, and HN: conceived and designed the experiments; LV, $\mathrm{KB}-\mathrm{H}, \mathrm{DH}, \mathrm{NB}, \mathrm{SB}, \mathrm{FR}$, and GB: performed the experiments; LV, MK-B, KB-H, NB, and GB: analyzed the data; HM, KB-H, and MK-B: wrote the paper.

\section{FUNDING}

This work was supported by the grant KO 3552/4-1 (German Research Council). 


\section{REFERENCES}

1. Brinkmann V, Reichard U, Goosmann C, Fauler B, Uhlemann Y, Weiss DS, et al. Neutrophil extracellular traps kill bacteria. Science (2004) 303:1532-5. doi:10.1126/science. 1092385

2. von Köckritz-Blickwede M, Nizet V. Innate immunity turned inside-out: antimicrobial defense by phagocyte extracellular traps. J Mol Med (Berl) (2009) 87(8):775-83. doi:10.1007/s00109-009-0481-0

3. Fuchs TA, Abed U, Goosmann C, Hurwitz R, Schulze I, Wahn V, et al. Novel cell death program leads to neutrophil extracellular traps. J Cell Biol (2007) 176:231-41. doi:10.1083/jcb.200606027

4. Papayannopoulos V, Metzler KD, Hakkim A, Zychlinsky A. Neutrophil elastase and myeloperoxidase regulate the formation of neutrophil extracellular traps. J Cell Biol (2010) 191(3):677-91. doi:10.1083/jcb.201006052

5. Yost CC, Cody MJ, Harris ES, Thornton NL, McInturff AM, Martinez ML, et al. Impaired neutrophil extracellular trap (NET) formation: a novel innate immune deficiency of human neonates. Blood (2009) 113(25):6419-27. doi:10.1182/blood-2008-07-171629

6. Nishinaka Y, Arai T, Adachi S, Takaori-Kondo A, Yamashita K. Singlet oxygen is essential for neutrophil extracellular trap formation. Biochem Biophys Res Commun (2011) 413(1):75-9. doi:10.1016/j.bbrc.2011.08.052

7. Kirchner T, Möller S, Klinger M, Solbach W, Laskay T, Behnen M. The impact of various reactive oxygen species on the formation of neutrophil extracellular traps. Mediators Inflamm (2012) 2012:849136. doi:10.1155/2012/849136

8. Metzler KD, Goosmann C, Lubojemska A, Zychlinsky A, Papayannopoulos V. A myeloperoxidase-containing complex regulates neutrophil elastase release and actin dynamics during NETosis. Cell Rep (2014) 8(3):883-96. doi:10.1016/j.celrep.2014.06.044

9. Stoiber W, Obermayer A, Steinbacher P, Krautgartner WD. The role of reactive oxygen species (ROS) in the formation of extracellular traps (ETs) in humans. Biomolecules (2015) 5(2):702-23. doi:10.3390/biom5020702

10. Tahara E, Kadara H, Lacroix L, Lotan D, Lotan R. Activation of protein kinase $\mathrm{C}$ by phorbol 12-myristate 13-acetate suppresses the growth of lung cancer cells through KLF6 induction. Cancer Biol Ther (2009) 8(9):801-7. doi:10.4161/cbt.8.9.8186

11. Bylund J, Brown KL, Movitz C, Dahlgren C, Karlsson A. Intracellular generation of superoxide by the phagocyte NADPH oxidase: How, where, and what for? Free Radic Biol Med (2010) 49:1834-45. doi:10.1016/ j.freeradbiomed.2010.09.016

12. El Benna J, Faust RP, Johnson JL, Babior BM. Phosphorylation of the respiratory burst oxidase subunit 47 phox as determined by two-dimensional phosphopeptide mapping. Phosphorylation by protein kinase C, protein kinase A, and a mitogen-activated protein kinase. J Biol Chem (1996) 271(11):6374-8. doi:10.1074/jbc.271.11.6374

13. Dekker LV, Leitges M, Altschuler G, Mistry N, McDermott A, Roses J, et al. Protein kinase C-beta contributes to NADPH oxidase activation in neutrophils. Biochem J (2000) 347(Pt 1):285-9.

14. Hakkim A, Fuchs TA, Martinez NE, Hess S, Prinz H, Zychlinsky A, et al. Activation of the Raf-MEK-ERK pathway is required for neutrophil extracellular trap formation. Nat Chem Biol (2011) 7:75-7. doi:10.1038/nchembio.496

15. Mendes AF, Carvalho AP, Caramona MM, Lopes MC. Diphenyleneiodonium inhibits NF-kappaB activation and iNOS expression induced by IL-1beta: involvement of reactive oxygen species. Mediators Inflamm (2001) 10(4):20915. doi:10.1080/09629350120080401

16. Arroyo A, Modrianský M, Serinkan FB, Bello RI, Matsura T, Jiang J, et al. NADPH oxidase-dependent oxidation and externalization of phosphatidylserine during apoptosis in Me2SO-differentiated HL-60 ells: role in phagocytic clearance. J Biol Chem (2002) 277:49965. doi:10.1074/jbc.M204513200

17. Scheel-Toellner D, Wang K, Craddock R, Webb PR, McGettrick HM, Assi LK, et al. Reactive oxygen species limit neutrophil life span by activating death receptor signaling. Blood (2004) 104(8):2557-64. doi:10.1182/ blood-2004-01-0191

18. Galanis A, Pappa A, Giannakakis A, Lanitis E, Dangaj D, Sandaltzopoulos R. Reactive oxygen species and HIF-1 signalling in cancer. Cancer Lett (2008) 266(1):12-20. doi:10.1016/j.canlet.2008.02.028

19. Peyssonnaux C, Datta V, Cramer T, Doedens A, Theodorakis EA, Gallo RL. HIF- $1 \alpha$ expression regulates the bactericidal capacity of phagocytes. J Clin Invest (2005) 115(7):1806-15. doi:10.1172/JCI23865
20. Zinkernagel AS, Johnson RS, Nizet V. Hypoxia inducible factor (HIF) function in innate immunity and infection. J Mol Med (Berl) (2007) 85(12):1339-46. doi:10.1007/s00109-007-0282-2

21. Branitzki-Heinemann K, Okumura CY, Völlger L, Kawakami Y, Kawakami T, Naim HY, et al. Novel role of the transcription factor HIF- $1 \alpha$ in the formation of mast cell extracellular traps. Biochem J (2012) 446(1):159-63. doi:10.1042/ BJ20120658

22. McInturff AM, Cody MJ, Elliott EA, Glenn JW, Rowley JW, Rondina MT, et al. Mammalian target of rapamycin regulates neutrophil extracellular trap formation via induction of hypoxia-inducible factor $1 \alpha$. Blood (2012) 120(15):3118-25. doi:10.1182/blood-2012-01-405993

23. Itakura A, McCarty OJ. Pivotal role for the mTOR pathway in the formation of neutrophil extracellular traps via regulation of autophagy. Am J Physiol Cell Physiol (2013) 305(3):C348-54. doi:10.1152/ajpcell.00108.2013

24. Hervouet E, Cízková A, Demont J, Vojtísková A, Pecina P, Franssen-van Hal NL, et al. HIF and reactive oxygen species regulate oxidative phosphorylation in cancer. Carcinogenesis (2008) 29(8):1528-37. doi:10.1093/carcin/ bgn 125

25. Völlger L, Akong-Moore KA, Cox L, Goldmann O, Wang Y, Schäfer S, et al. Iron chelating agent desferrioxamine stimulates formation of neutrophil extracellular traps (NETs) in human blood-derived neutrophils. Biosci Rep (2016) 36:e00333. doi:10.1042/BSR20160031

26. Mecklenburgh KI, Walmsley SR, Cowburn AS, Wiesener M, Reed BJ, Upton PD, et al. Involvement of a ferroprotein sensor in hypoxia-mediated inhibition of neutrophil apoptosis. Blood (2002) 100(8):3008-16. doi:10.1182/ blood-2002-02-0454

27. Walmsley SR, Cowburn AS, Clatworthy MR, Morrell NW, Roper EC, Singleton V, et al. Neutrophils from patients with heterozygous germline mutations in the von Hippel Lindau protein (pVHL) display delayed apoptosis and enhanced bacterial phagocytosis. Blood (2006) 108(9):3176-8. doi:10.1182/blood-2006-04-018796

28. Wang JS, Liu HC. Systemic hypoxia enhances bactericidal activities of human polymorphonuclear leuocytes. Clin Sci (2009) 116(11):805-17. doi:10.1042/ CS20080224

29. Wang JS, Chiu YT. Systemic hypoxia enhances exercise-mediated bactericidal and subsequent apoptotic responses in human neutrophils. J Appl Physiol (2009) 107(4):1213-22. doi:10.1152/japplphysiol.00316.2009

30. Berends ET, Horswill AR, Haste NM, Monestier M, Nizet V, von KöckritzBlickwede M. Nuclease expression by Staphylococcus aureus facilitates escape from neutrophil extracellular traps. J Innate Immun (2010) 6:576-86. doi:10.1159/000319909

31. von Köckritz-Blickwede M, Chow O, Ghochani M, Nizet V. Visualization and functional evaluation of phagocyte extracellular traps. Method Microbiol (2010) 37:139-60. doi:10.1016/S0580-9517(10)37007-3

32. Zeitouni NE, Fandrey J, Naim HY, von Köckritz-Blickwede M. Measuring oxygen levels in Caco-2 cultures. Hypoxia (2015) 3:53-66. doi:10.2147/ HP.S85625

33. Vanderkooi JM, Maniara G, Green TJ, Wilson DF. An optical method for measurement of dioxygen concentration based upon quenching of phosphorescence. J Biol Chem (1987) 262(12):5476-82.

34. Carreau A, El Hafny-Rahbi B, Matejuk A, Grillon C, Kieda C. Why is the partial oxygen pressure of human tissues a crucial parameter? Small molecules and hypoxia. J Cell Mol Med (2011) 15(6):1239-53. doi:10.1111/j.1582-4934.2011.01258.x

35. Brogden G, Propsting M, Adamek M, Naim HY, Steinhagen D. Isolation and analysis of membrane lipids and lipid rafts in common carp (Cyprinus carpio L.). Comp Biochem Physiol B Biochem Mol Biol (2014) 169:9-15. doi:10.1016/j.cbpb.2013.12.001

36. Willenborg J, Fulde M, de Greeff A, Rohde M, Smith HE, ValentinWeigand $\mathrm{P}$, et al. Role of glucose and CcpA in capsule expression and virulence of Streptococcus suis. Microbiology (2011) 157(Pt 6):1823-33. doi:10.1099/mic.0.046417-0

37. Melican K, Boekel J, Månsson LE, Sandoval RM, Tanner GA, Källskog O, et al. Bacterial infection-mediated mucosal signalling induces local renal ischaemia as a defence against sepsis. Cell Microbiol (2008) 10(10):1987-98. doi:10.1111/j.1462-5822.2008.01182.x

38. Campbell EL, Bruyninckx WJ, Kelly CJ, Glover LE, McNamee EN, Bowers BE, et al. Transmigrating neutrophils shape the mucosal microenvironment 
through localized oxygen depletion to influence resolution of inflammation. Immunity (2014) 40(1):66-77. doi:10.1016/j.immuni.2013.11.020

39. Schaffer K, Taylor CT. The impact of hypoxia on bacterial infection. FEBS $J$ (2015) 282(12):2260-6. doi:10.1111/febs.13270

40. Kirchner T. Die Bedeutung reaktiver Sauerstoffspezies für die Bildung von Neutrophil Extracellular Traps (NETs). [Dissertation/Doctoral Thesis]. Lübeck: Universität zu Lübeck (2013). Available from: https://www.deutsche-digitale-bibliothek.de/binary/2OGR5WY6BE3IKL3CQ65IEVHB4STUJX5O/ full/1.pdf

41. Kirchner T, Hermann E, Möller S, Klinger M, Solbach W, Laskay T, et al. Flavonoids and 5-aminosalicylic acid inhibit the formation of neutrophil extracellular traps. Mediators Inflamm (2013) 2013:710239. doi:10.1155/ 2013/710239

42. Liu Y, Cox SR, Morita T, Kourembanas S. Hypoxia regulates vascular endothelial growth factor gene expression in endothelial cells. Identification of a $5^{\prime}$ enhancer. Circ Res (1995) 77:638-43.

43. Forsythe JA, Jiang BH, Iyer NV, Agani F, Leung SW, Koos RD, et al. Activation of vascular endothelial growth factor gene transcription by hypoxia-inducible factor 1. Mol Cell Biol (1996) 16:4604-13. doi:10.1128/MCB.16.9.4604

44. Peyssonnaux C, Boutin AT, Zinkernagel AS, Datta V, Nizet V, Johnson RS. Critical role of HIF-1 $\alpha$ in keratinocyte defense against bacterial infection. J Invest Dermatol (2008) 128(8):1964-8. doi:10.1038/jid.2008.27

45. Neumann A, Brogden G, Jerjomiceva N, Brodesser S, Naim HY, von Köckritz-Blickwede M. Lipid alterations in human blood-derived neutrophils lead to formation of neutrophil extracellular traps. Eur JCell Biol (2014) 93(8-9):347-54. doi:10.1016/j.ejcb.2014.07.005

46. Chow OA, von Köckritz-Blickwede M, Bright AT, Hensler ME, Zinkernagel AS, Cogen AL, et al. Statins enhance formation of phagocyte extracellular traps. Cell Host Microbe (2010) 8(5):445-54. doi:10.1016/j.chom.2010.10.005

47. Malachowa N, Kobayashi SD, Freedman B, Dorward DW, DeLeo FR. Staphylococcus aureus leukotoxin GH promotes formation of neutrophil extracellular traps. J Immunol (2013) 15:6022-9. doi:10.4049/jimmunol. 1301821

48. Pilsczek FH, Salina D, Poon KK, Fahey C, Yipp BG, Sibley CD, et al. A novel mechanism of rapid nuclear neutrophil extracellular trap formation in response to Staphylococcus aureus. J Immunol (2010) 185(12):7413-25. doi:10.4049/jimmunol.1000675

49. Gonzalez DJ, Corriden R, Akong-Moore K, Olson J, Dorrestein PC, Nizet V. N-terminal ArgD peptides from the classical Staphylococcus aureus Agr system have cytotoxic and proinflammatory activities. Chem Biol (2014) 21:1457-62. doi:10.1016/j.chembiol.2014.09.015

50. Steinberg BE, Grinstein S. Unconventional roles of the NADPH oxidase: signaling, ion homeostasis, and cell death. Sci STKE (2007) 379:pe11. doi:10.1126/stke.3792007pe11

51. Zeitouni NE, Dersch P, Naim HY, von Köckritz-Blickwede M. Hypoxia decreases invasin-mediated Yersinia enterocolitica internalization into Caco-2 cells. PLoS One (2016) 11(1):e0146103. doi:10.1371/journal.pone.0146103

52. Cedervall J, Olsson AK. NETosis in cancer. Oncoscience (2015) 2(11):900-1. doi:10.18632/oncoscience.264

53. Tohme S, Yazdani HO, Al-Khafaji AB, Chidi AP, Loughran P, Mowen K, et al. Neutrophil extracellular traps promote the development and progression of liver metastases after surgical stress. Cancer Res (2016) 76(6):1367-80. doi:10.1158/0008-5472.CAN-15-1591

54. Alfaro C, Teijeira A, Oñate C, Pérez G, Sanmamed MF, Andueza MP, et al. Tumor-produced interleukin-8 attracts human myeloid-derived suppressor cells and elicits extrusion of neutrophil extracellular traps (NETs). Clin Cancer Res (2016) 22(15):3924-36. doi:10.1158/1078-0432.CCR-15-2463

Conflict of Interest Statement: The authors declare that the research was conducted in the absence of any commercial or financial relationships that could be construed as a potential conflict of interest.

Copyright (C) 2016 Branitzki-Heinemann, Möllerherm, Völlger, Husein, de Buhr, Blodkamp, Reuner, Brogden, Naim and von Köckritz-Blickwede. This is an open-access article distributed under the terms of the Creative Commons Attribution License (CC $B Y)$. The use, distribution or reproduction in other forums is permitted, provided the original author(s) or licensor are credited and that the original publication in this journal is cited, in accordance with accepted academic practice. No use, distribution or reproduction is permitted which does not comply with these terms. 